\title{
CCXXXVI.-The Tautomerism of Thioanilides.
}

\section{By Percy May.}

IN order to decide which of the two possible tautomeric formulæ better represents thiobenzanilide itself, the two methyl derivatives have been examined and their properties compared with those of the parent substance.

The absorption curve of the parent substance closely resembles

F1G. 1.

Oscillation frequencies.

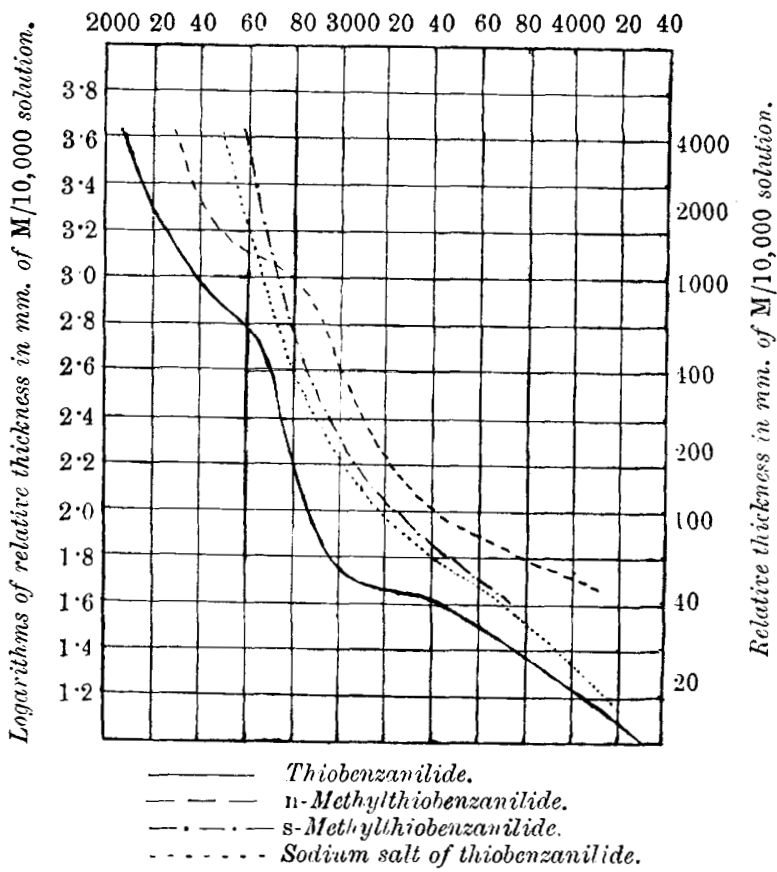

that of the $N$-methyl derivative (I). The curves for the sodium salt and the $S$-methyl derivative (II) are practically identical, but differ in character from, and show less general absorption* than, those of the parent substance and $N$-methyl derivative.

$$
\mathrm{O}_{6} \mathrm{H}_{5} \cdot \underset{+}{\mathrm{I}}-\underset{\mathrm{C}}{\mathrm{N}} \mathrm{H}_{3} \underset{\mathrm{S}}{\mathrm{C}} \cdot \mathrm{C}_{6} \mathrm{H}_{5}
$$

* In comparing the general ahsorption, only the upper portion of the curves, where there are neither bands nor incipient bands, is considered. 
The spectroscopic evidence, therefore, is in favour of the usual thioketone formula for thiobenzanilide.

On the other hand, the sodium salt and $S$-methyl derivative (III) of thioacetanilide show greater general absorption than the $N$-methyl derivative (IV). This is in accordance with the observation that substances containing double bonds in the conjugated

FIG. 2.

Oscillation frequencies.

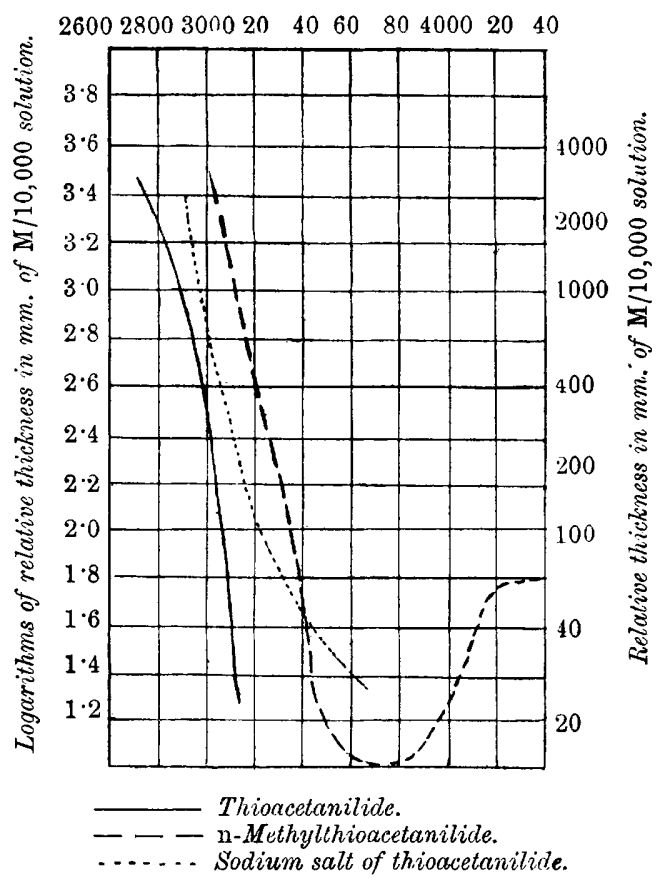

position show greater general absorption than isomeric compounds containing the double bonds in the unconjugated position:

$$
\begin{array}{r}
\mathrm{C}_{6} \mathrm{H}_{5} \cdot \mathrm{N}: \underset{\mathrm{S}}{\mathrm{S}} \cdot \mathrm{CH}_{3} \\
\mathrm{CH}_{3}
\end{array}
$$

(III.)<smiles>CC(=O)N(C)c1ccccc1</smiles>

(IV.)

In the case of thioacetanilide, the spectroscopic evidence is not very conclusive, but here also it appears to favour the thioketone structure.

On attempting to methylate thiobenzanilide in neutral solvents decomposition always took place, the sulphur being eliminated as 
methyl sulphide. When the reaction was carried out in hot xylene solution the chief product of the reaction was sulphanilic acid. The small amount of water present in the solvent brings about this complete decomposition, which probably takes place in two stages:

$$
\begin{gathered}
\mathrm{C}_{6} \mathrm{H}_{5} \cdot \mathrm{NH} \cdot \mathrm{CS} \cdot \mathrm{C}_{6} \mathrm{H}_{5}+\left(\mathrm{CH}_{3}\right)_{2} \mathrm{SO}_{4}+\mathrm{H}_{2} \mathrm{O}= \\
\quad \mathrm{C}_{6} \mathrm{H}_{5} \cdot \mathrm{NH} \cdot \mathrm{CO} \cdot \mathrm{C}_{6} \mathrm{H}_{5}+\left(\mathrm{CH}_{3}\right)_{2} \mathrm{~S}+\mathrm{H}_{2} \mathrm{SO}_{4}, \\
\mathrm{C}_{6} \mathrm{H}_{5} \cdot \mathrm{NH} \cdot \mathrm{CO} \cdot \mathrm{C}_{6}^{\prime} \mathrm{H}_{5}+\mathrm{H}_{2} \mathrm{SO}_{4}=\mathrm{HSO}_{3} \cdot \mathrm{C}_{6} \mathrm{H}_{4} \cdot \mathrm{NH}_{2}+\mathrm{C}_{6} \mathrm{H}_{5} \cdot \mathrm{CO}_{2} \mathrm{H} .
\end{gathered}
$$

In some solvents the first stage, formation of methyl sulphide, is complete at room temperature.

\section{ExPERIMENTAL.}

S-Methylthiobenzanilide was obtained as a white, crystalline precipitate on adding an excess of methyl sulphate to a solution of thiobenzanilide in aqueous sodium hydroxide. On crystallisation from aqueous alcohol it separates in colourless, fine needles, melting at $63--64^{\circ}$. It is almost insoluble in cold water or alkali, but readily soluble in most organic solvents :

0.1350 gave $0.3640 \mathrm{CO}_{2}$ and $0.0717 \mathrm{H}_{2} \mathrm{O} . \mathrm{C}=73.53 ; \mathrm{H}=5.90$. $\mathrm{C}_{14} \mathrm{H}_{13} \mathrm{NS}$ requires $\mathrm{C}=73.94 ; \mathrm{H}=5.77$ per cent.

\section{Action of Methyl Sulphate on Thiobenzanilide in Neutral Solvents.}

Methyl sulphate readily reacts with thiobenzanilide in neutral solvents, such as benzene, xylene, nitrobenzene, or methyl alcohol; for example, 5 grams of thiobenzanilide were dissolved in xylene, and 5 grams of methyl sulphate added. A red colour was produced, and on warming a rapid evolution of methyl sulphide occurred, and a solid separated. This was collected, purified, and recrystallised from hot water, and was then identified as sulphanilic acid. (Found, after drying at $120^{\circ}, \mathrm{C}=41.3 ; \mathrm{H}=4.55$. M.W. $=174$. $\mathrm{C}_{6} \mathrm{H}_{7} \mathrm{O}_{3} \mathrm{NS}$ requires $\mathrm{C}=41.6 ; \mathrm{H}=4.05$ per cent. $\mathrm{M} . \mathrm{W} .=173$.)

Methyl sulphide is also formed when the reaction is carried out in the other solvents mentioned above, and when methyl iodide reacts with a methyl-alcoholic solution of thiobenzanilide.

\section{N-Methylthiobenzanilide.}

Methylbenzanilide was obtained by the action of benzoyl chloride on a pyridine solution of methylaniline, and was finally obtained in large, transparent crystals melting at $58^{\circ}$. Four grams of phosphorus pentasulphide, 2 grams of phosphorus trisulphide, and 6 grams of methylbenzanilide were powdered, mixed, and heated for half-an-hour on the water-bath. The product was extracted 
WERNER:'TDECOMPOSITION OF CARBAMIDE, ETC.

with ether, and the crude substance so obtained extracted with cold alcohol, which dissolved out some dark-coloured impurities. The residue was crystallised from ether, and recrystallised from aqueous alcohol, from which it separates in small, yellow cubes, melting at $90-91^{\circ}$ :

0.1485 gave $0.1570 \mathrm{BaSO}_{4} . \quad \mathrm{S}=14.52$.

$\mathrm{C}_{14} \mathrm{H}_{13} \mathrm{NS}$ requires $\mathrm{S}=14 \cdot 11$ per cent.

My thanks are due to the Research Fund Committee of the Chemical Society for a grant towards the expenses of the investigation, and to Dr. Smiles, who kindly supplied me with the thiobenzanilide.

UNIVERSITY OF LONDON, University College. 